\title{
Performance of hemp-FRCM-strengthened beam subjected to cyclic loads
}

\author{
$\oplus$ L. Mercedes ${ }^{\mathrm{a}} \bowtie, \oplus \mathrm{V}$. Mendizábal ${ }^{\mathrm{b}}, \oplus \mathrm{E}$. Bernat-Maso ${ }^{\mathrm{a}, \mathrm{c}}, \oplus \mathrm{L} . \mathrm{Gil}^{\mathrm{a}}$ \\ a. Department of Strength of Materials, Polytechnic University of Catalonia, (Terrassa, Spain) \\ b. LITEM Laboratory for Technological Innovation of Structures and Materials, (Terrassa, Spain) \\ c. Serra Húnter Fellow, Polytechnic University of Catalonia, (Terrassa, Spain) \\ $凶$ :luis.enrique.mercedes@upc.edu
}

\begin{abstract}
Fabric-reinforced cementitious matrix (FRCM) composites are materials that are usually applied to strengthen existing structures. In this study, a hemp mesh coated with epoxy was manufactured and combined with a cementitious matrix to strengthen a concrete beam. This beam was subjected to bending cyclic loading tests and a nondestructive modal analysis test. The modal analysis was performed to determine the dynamic elastic properties of the beam under pre-cracking, post-cracking, and strengthened conditions. The beam stiffness increased following strengthening with hemp-FRCM. The results of the experimental cyclic loading test showed that the hemp-FRCM system improved the load-bearing capacity of the beam at the service limit state by $42 \%$. Analytical and numerical models were adjusted and validated using the experimental results, and both proved to be effective calculation tools. The models accurately reproduced the behaviour of the FRCM-strengthened concrete beam if the strengthening connection could prevent sliding and mortar debonding failures.
\end{abstract}

KEYWORDS: Cyclic loading test; Concrete beam; Vegetal fibres; Hemp; FRCM.

Citation/Citar como: Mercedes, L.; Mendizábal, V.; Bernat-Maso, E.; Gil, L. (2022) Performance of hemp-FRCM-strengthened beam subjected to cyclic loads. Mater. Construcc. 72 [345], e270. https://doi.org/10.3989/mc.2022.07721.

RESUMEN: Comportamiento de viga reforzada con FRCM de cáñamo sometida a cargas cíclicas. Los compuestos de matriz cementicia reforzada con tejidos (FRCM) son materiales que generalmente se aplican para el refuerzo de las estructuras existentes. En este estudio, se fabricó una malla de cáñamo recubierta con epoxi y se combinó con una matriz cementicia para reforzar una viga de hormigón. Esta viga se sometió a ensayos de carga cíclica de flexión y un ensayo no destructivo de análisis modal. El análisis modal se realizó para determinar las propiedades dinámicas elásticas de la viga en condiciones de pre-fisuración, postfisuración y reforzado. La rigidez de la viga aumentó después del reforzar con FRCM de cáñamo. Los resultados del ensayo de carga cíclica experimental mostraron que el sistema de FRCM de cáñamo mejoró la capacidad de carga de la viga en el estado límite de servicio en un $42 \%$. Los modelos analíticos y numéricos se ajustaron y validaron utilizando los resultados experimentales, y ambos demostraron ser herramientas de cálculo efectivas. Los modelos reproducen con precisión el comportamiento de la viga de hormigón reforzado con FRCM cuando la conexión de refuerzo podía evitar fallas por deslizamiento y desprendimiento del mortero.

PALABRAS CLAVE: Ensayo de carga cíclica; Viga de hormigón; Fibras vegetales; Cáñamo; FRCM.

Copyright: (C2022 CSIC. This is an open-access article distributed under the terms of the Creative Commons Attribution 4.0 International (CC BY 4.0) License. 


\section{INTRODUCTION}

In recent decades, the damage recorded as a result of dynamic actions (such as that caused by heavy road and rail traffic as well as heavy machinery) has led to research being conducted on structural strengthening and rehabilitation. Therefore, there is an evident need to develop strengthening techniques that allow the structures to be maintained for a longer period of time at a competitive global cost (considering environmental factors) rather than demolish and build again.

Consequently, over the years, there has been a development of increasingly efficient and sustainable structural reinforcement techniques that respond to the accumulated damage over time, such as the fabric-reinforced cementitious matrix (FRCM).

FRCM is a composite material formed by a mesh embedded in an inorganic matrix that has emerged as an alternative to the organic matrix of fibre-reinforced polymers (FRPs) (1). As the FRCM has less toxic emissions, greater fire resistance (2), and water vapour permeability, among other advantages, researchers see it as a possible substitute for FRPs (3) in the field of strengthening and rehabilitation of structures.

In the case of reinforced concrete (RC) beams, several studies have been conducted to study the contribution of FRCM strengthening systems to the behaviour of beams subjected to bending $(4,5)$ and shear (6). A study published by Escrig et al. (7) applied five types of FRCMs as flexural reinforcements on an RC beam. The results show that the FRCM contributed to an increase in the flexural capacity and flexural stiffness of the strengthened beams, but their ductility decreased. In addition, all examined FRCM materials incremented the flexural moment acting at the first crack time, flexural yielding moment, and flexural stiffness. Comparing them with unstrengthened beams, the average increases were approximately $35 \%, 27 \%$, and $135 \%$, respectively.

However, FRCM compounds have two technical drawbacks that need to be overcome: (i) their high stiffness makes it difficult to dissipate energy against dynamic stresses, resulting in stress concentration on the existing structure (8), and (ii) obtaining the synthetic fibres used in these composites is economically and environmentally costly (9).

Therefore, the use of natural resources and sustainable materials is a topic that is receiving increasing attention from the scientific community. The use of vegetable fibres as reinforcements of polymers and mortars is an example of this. Because of the demonstrated mechanical properties of fibres such as flax, hemp, sisal, jute, and banana, along with their low cost, low density, recyclability, and biodegradability, vegetal fibres have become an effective alternative to synthetic fibres (10).

Despite the numerous advantages that vegetal fi- bres have over synthetic fibres in terms of strength capacity, their use is limited by their average mechanical performance. However, in a study published by Wambua et al. (9), the mechanical properties of natural fibre composite materials (with an organic matrix) compare favourably with the properties corresponding to fibreglass composites, suggesting that natural fibre composites have the potential to replace those of glass fibres in some applications where their mechanical properties conform to the requirements.

In the field of engineering, numerous studies have focused on the development of composites by incorporating vegetal fibres as structural reinforcements. An example of this is the study by Huang et al. (11), who strengthened beams with flax-FRP, resulting in an increase in the maximum load capacity between $15.5 \%$ and $112.2 \%$. Beams reinforced with more layers of flax (six layers) had a higher breaking load, ductility, and energy absorption capacity than those strengthened with fewer layers and control beams.

Numerous articles have addressed the behaviour of vegetal fibres in FRCMs $(9,11-13)$. The results obtained thus far demonstrate the great potential of vegetal fibres as reinforcements in FRCMs. Significantly better results were obtained by the FRCM of flax and hemp fibres in the studies mentioned above, owing to the high strength and stiffness presented by these fibres in comparison with those of other vegetal fibres such as sisal and cotton (14). Flax and hemp fibres are the most promising materials in the field of engineering.

The organic origin of vegetal fibres favours their degradation in the environment of cementitious matrix composites (15) owing to the high alkalinity and humidity cycles. Because of this drawback, some authors have studied the feasibility of applying treatments to avoid fibre degradation. One of these treatments is the coating of fibres with a resin (16).

Coating with resin affects the sustainability of vegetal fibres, as it increases their cost and generates toxicity. However, coating the meshes used in FRCM composites is a widely used technique. In some cases, this coating prevents fibre degradation within the cementitious matrix (17), and in other cases, it improves the mechanical properties and the bond of the meshes with the matrix $(18,19)$.

Regarding the experimental study of RC beams subjected to cyclic loads, the study published by Shao and Billington (20) presented two possible failure paths of flexural members with different reinforcing ratios $(0.1 \%-2.10 \%)$ and two types of reinforcing steel (A615 Grade 60 and A1035 Grade 100). They conducted monotonic and cyclic loading tests.

The authors have not found publications that report comprehensive experimental tests aimed at demonstrating the behaviour of RC beams strengthened with FRCM of vegetal fibres and subjected to cyclic loading. Therefore, this study aimed to analyse 
the behaviour of a beam subjected to cyclic loads and reinforced with hemp-FRCM. Non-destructive characterisation tests (modal analysis) were carried out on the control, cracked, and strengthened beams to evaluate the evolution of the dynamic modulus of elasticity. Based on the results of the cyclic flexural test and modal analysis of the beam, it was possible to develop an analytical and numerical model capable of reproducing the experimental behaviour of the beam strengthened with hemp-FRCM.

The results of this study demonstrate the ability of hemp-FRCMs to improve the structural response of an RC beam subjected to cyclic loads. Numerical and analytical procedures that could effectively reproduce experimental behaviour have also been presented.

\section{EXPERIMENTAL CAMPAIGN}

\subsection{Materials and methods}

\subsubsection{Reinforced concrete (RC) beam}

Two RC beam specimens were manufactured and tested. One of them was statically loaded under a three-point bending configuration until failure. The other was loaded in the same configuration until it cracked. After that, it was strengthened with hempFRCM and finally subjected to a bending cyclic loading test. Figure 1 shows the cross-sectional geometry and reinforcement details of the concrete beams. Their length was $4.5 \mathrm{~m}$. Both beams were cast from a single batch of concrete whose average 28-day compressive strength was $30 \mathrm{MPa}$ according to the procedures in EN 12390 (21). The steel grade was B-500-S. The reinforcement of the beam fulfils the minimum requirements of the EHE norm (22), but it is also weak enough against bending for the purposes of this study.

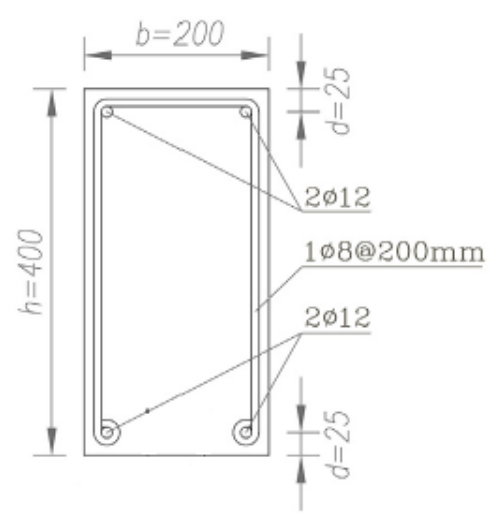

FigURE 1. Beam cross-section geometry and reinforcement details.

\subsubsection{FRCM composite}

\subsubsection{Mortar}

To prepare the strengthened beam, a single-component thixotropic mortar composed of cement, synthetic resins, and silica fume and reinforced with polyamide fibres was used. This mortar complies with the type R3 requirements as defined in UNEEN 1504-3 (23).

The control mortar specimens were tested in flexion, and the resulting halves were then tested under compression. These tests were performed according to EN 1015-11: 2000 (24). The averaged results of the compression and bending tests and other mechanical properties (supplied by the manufacturer) are summarised in Table 1.

TABLE 1. Properties of mortar.

\begin{tabular}{ll}
\hline Chemical composition (1) & $\begin{array}{l}\text { Prepared cement mortar improved } \\
\text { with synthetic resins and silica } \\
\text { fume and reinforced with polyam- } \\
\text { ide fibres }\end{array}$ \\
\hline Density of fresh mortar (1): & $2.1 \mathrm{~g} / \mathrm{cm}^{3}$ \\
Compressive strength (2): & $39.25 \mathrm{MPa}$ \\
Flexural strength (2): & $6.56 \mathrm{MPa}$ \\
\hline $\begin{array}{l}\text { (1) Supplied by manufacturer; (2) results of tests (EN 1015-11: } \\
\text { 2000) }\end{array}$
\end{tabular}

\subsubsection{Hemp mesh}

To obtain a mesh of hemp fibres with a load capacity comparable to that of synthetic fibre meshes, a hemp mesh was designed (see Figure 2a) using the procedure published in (15). To achieve a load capacity comparable to that of commercial synthetic meshes, its thickness was increased using a greater volume of fibres than that of commercial meshes of synthetic fibres. This design maintained sufficient spacing between tufts $(8 \mathrm{~mm})$ to ensure efficient interaction with the matrix.

A wooden rectangular support was assembled as a handloom to manufacture the meshes. The support size was $200 \times 4500 \mathrm{~mm}$ and had nails at its external boundaries (Figure $2 \mathrm{~b}$ ). The nails were positioned every $12.5 \mathrm{~mm}$ in the warp direction and $50 \mathrm{~mm}$ in the weft direction. These were useful for stretching and anchoring the yarns, making it possible to weave the mesh.

Once the mesh was weaved, it was coated with an epoxy resin using a brush. The epoxy employed to coat the yarns was a low-viscosity and high-adhesion resin. The mechanical properties of the resin are presented in Table 2, according to the information provided by the supplier. 


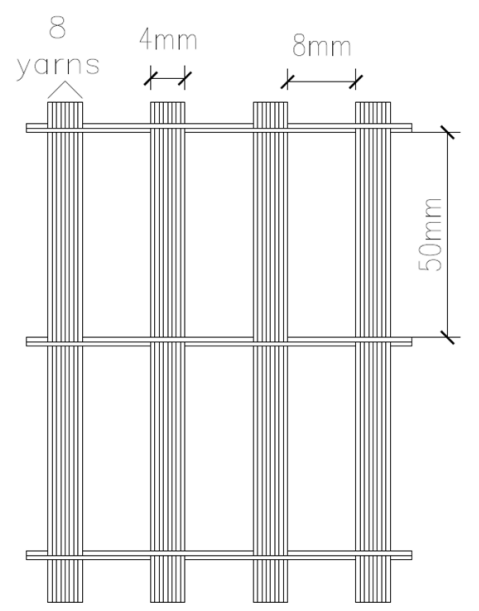

(a)

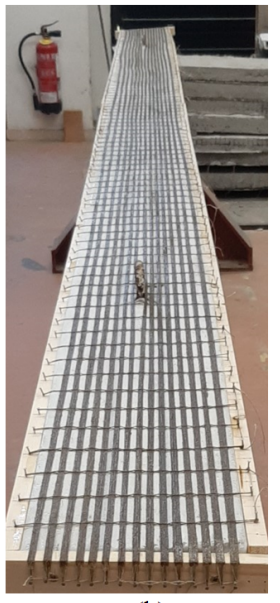

(b)

Figure 2. Design (a) and manufacturing (b) of hemp meshes.

TABLE 2. Mechanical properties of resin.

\begin{tabular}{lc}
\hline Properties & Epoxy \\
\hline Density $\left(\mathrm{g} / \mathrm{cm}^{3}\right):$ & 1.05 \\
Tensile strength $(\mathrm{MPa}):$ & $22.9 \pm 4$ \\
Elongation $(\%):$ & $18.2 \pm 7$ \\
Flexural strength $(\mathrm{MPa}):$ & No break \\
Flexural modulus $(\mathrm{MPa}):$ & 233.1 \\
\hline
\end{tabular}

The mechanical properties of the yarn are listed in Table 3. These data were previously presented in (14) for the same hemp yarn.

TABLE 3. Properties of yarn with and without coating.

\begin{tabular}{lcc}
\hline & \multicolumn{2}{c}{ Hemp } \\
Properties & Without epoxy & $\begin{array}{c}\text { With } \\
\text { epoxy }\end{array}$ \\
\hline Yarn diameter $(\mathrm{mm})$ & 0.5 \\
Yarn linear density $(\mathrm{g} / \mathrm{m})$ & 0.40 & 0.89 \\
Yarn volumetric density $\left(\mathrm{g} / \mathrm{cm}^{3}\right)$ & 2.04 & 4.54 \\
Epoxy/yarn length $(\mathrm{g} / \mathrm{m})$ & - & 0.5 \\
Tensile strength $(\mathrm{MPa})$ & 295.54 & 520.76 \\
Strain $(\%)$ & 1.03 & 1.30 \\
Young's Modulus $(\mathrm{GPa})$ & 26.33 & 38.74 \\
\hline
\end{tabular}

Before applying the FRCM strengthening layer to the beam, the face to be strengthened was moistened. Subsequently, the first layer of mortar was applied, and the mesh was placed such that it adhered to the mortar. Finally, the strengthened beam was finished by covering the mesh with another layer of mortar, leaving the mesh completely embedded (thickness of the FRCM $=10 \mathrm{~mm}$ ).

\subsection{Non-destructive test and modal analysis}

The experimental modal analysis fits into the category of non-destructive tests with input-output experimental modal identification, in which different points are excited and the vibration response (in terms of acceleration) is measured at a fixed point. In particular, the proposed experimental campaign aimed to capture the vibration modes (shape, frequency, and damping) and analyse how cracking and strengthening patterns affected them. The procedure described in (25) was followed to perform the tests.

Three modal analyses were undertaken for the same beam: one before strengthening (pre-cracking), one post-cracking, and the other after curing the strengthening system. To carry out the experimental modal analysis, 36 points were defined on half of the strengthened face of the beam, forming a grid of 12 rows and 3 columns.

A unidirectional accelerometer (Brüel \& Kjær piezoelectric charge accelerometer type 4370 with charge converter type 2646 , sensitivity of $10.11 \mathrm{pC} /$ $\mathrm{ms}^{-2}$, and measuring range of up to $4.8 \mathrm{kHz}$ ) was placed asymmetrically to capture as many vibration modes as possible. This sensor was oriented along the vertical direction and was attached to a transmission plate, which was bonded to the beam using cyanoacrylate, as previously described (25).

The beam was physically supported by a bridge crane during modal testing, with no additional constraints. The modal analysis was repeated in all the beam states (pre-cracking, post-cracking, and strengthened) with exactly the same configuration and laboratory conditions to obtain comparable results. The grid used to define the impact points was maintained.

A numerical modal analysis of the beam was implemented using Abaqus ${ }^{\mathrm{TM}}$ 6.14-4 (26) to compare its results with the modal experimental data. From the numerical vs. experimental fitting, the dynamic Young's modulus was indirectly obtained. For this numerical modal analysis, a deformable solid was used to model the concrete parts (see Section 4.3). The geometry corresponded to that of the control beam.

\subsubsection{Modal analysis results}

Only the second bending vibration mode was observed for all the modal analysis tests. The third bending vibration mode was clearly observed in the pre-cracking state. The values of the corresponding 
TABLE 4. Modal analysis: experimental and numerical results.

\begin{tabular}{|c|c|c|c|c|c|}
\hline \multicolumn{2}{|c|}{ Vibration modes } & \multicolumn{2}{|c|}{$2^{\text {nd }}$ bending mode } & \multicolumn{2}{|c|}{$3^{\text {rd }}$ bending mode } \\
\hline Modal analysis & beam state & $\omega(\mathbf{H z})$ & $\xi(\%)$ & $\omega_{\mathrm{u}}(\mathrm{Hz})$ & $\xi_{u}(\%)$ \\
\hline \multirow{3}{*}{ Experimental } & Pre-cracking & 202 & 0.74 & 379 & 0.572 \\
\hline & Post-cracking & 135 & 1.45 & - & - \\
\hline & Strengthened & 179 & 1.6 & - & - \\
\hline \multirow{3}{*}{ Numerical } & Pre-cracking & 201.77 & - & 372.64 & - \\
\hline & Post-cracking & 135.68 & - & - & - \\
\hline & Strengthened & 178.75 & - & - & - \\
\hline
\end{tabular}

TABLE 5. Dynamic elastic modulus.

\begin{tabular}{|c|c|c|c|c|c|}
\hline Beam state & $\begin{array}{l}\text { Dynamic modulus } \\
\qquad E_{d}(G P a)\end{array}$ & $\begin{array}{c}\text { Static modulus E } \\
\text { (GPa) }\end{array}$ & $\begin{array}{c}\text { Flexural stiffness EI } \\
\left(\mathrm{kN}-\mathrm{m}^{2}\right)\end{array}$ & & $\begin{array}{c}\text { Variation EI } \\
\qquad(\%)\end{array}$ \\
\hline Pre-cracking & 28.58 & 8.57 & 9145.60 & & \\
\hline Post-cracking & 11.67 & 3.50 & 3734.40 & 59 & vs Pre-cracking \\
\hline Strengthened & 22.13 & 6.64 & 13831.25 & 270 & vs Post-cracking \\
\hline
\end{tabular}

frequencies $(\omega)$ and damping ratios $(\zeta)$ are summarised in Table 4, which also includes the numerical results.

The elastic modulus used in the simulation was adjusted to fit the simulated vibration frequencies to the experimental values. This comparison was performed for each state (pre-cracking, post-cracking, and strengthened), resulting in a particular dynamic elastic modulus $\left(E_{d}\right)$ for each case Table 5. summarises the results.

Table 5 also includes the static elastic modulus (E) and flexural stiffness (EI) for each case. The static elastic modulus was equal to $30 \%$ of the dynamic elastic modulus. This relationship between the static and dynamic elastic modulus was suggested by (27) and was also implemented in the numerical model presented in this article.

The figures in Table 5 show that the flexural stiffness was significantly reduced when the beam cracked (59\% reduction). Meanwhile, strengthening caused an increase of $270 \%$ in the elastic modulus in comparison with the post-cracked state. This demonstrates the effective contribution of the FRCM to increase the stiffness of the damaged beams, although the initial stiffness was not reached.

\subsection{Static and cyclic bending load tests}

The control beam was subjected to a static load test (contrast element), and the beam strengthened with the hemp-FRCM was subjected to cyclic load tests to study its effectiveness.

For both cases, the beams were subjected to threepoint bending at a displacement rate of $1 \mathrm{~mm} / \mathrm{s}$, which was imposed by a $250 \mathrm{kN}$ range oleo-hydraulic actuator. Measurements of deflection were monitored during the experiment using two external potentiometer sensors (see Figure 3). An HBM MGC Plus data acquisition system was used to record data from the two potentiometers and the actuator simultaneously, at a rate of $50 \mathrm{~Hz}$.

Although the four-point bending test configuration is commonly preferred to study flexural response, real structures are subjected to bending and shear efforts simultaneously. Thus, a three-point bending test was selected to better represent the real concomitance of the flexural and bending efforts in this research.

The cyclic loading protocol was adopted based on FEMA 461 (28), which comprises cycles of step- 


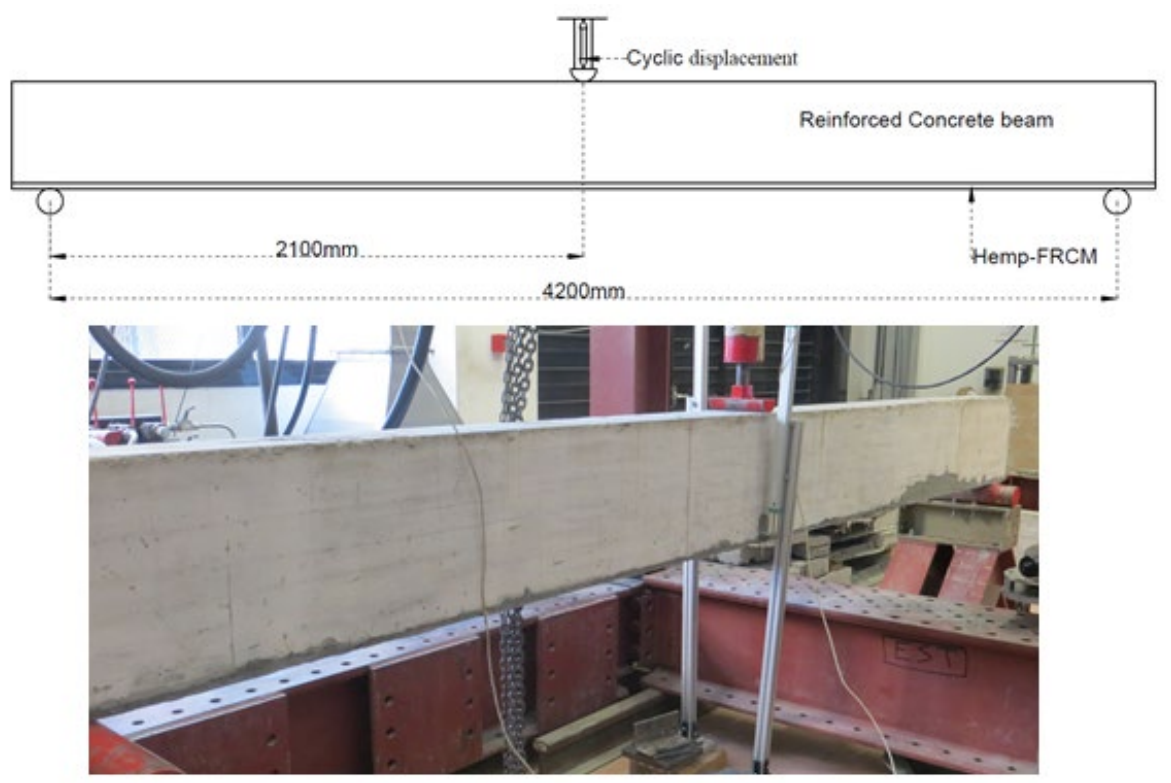

FIGURE 3. Test set up.

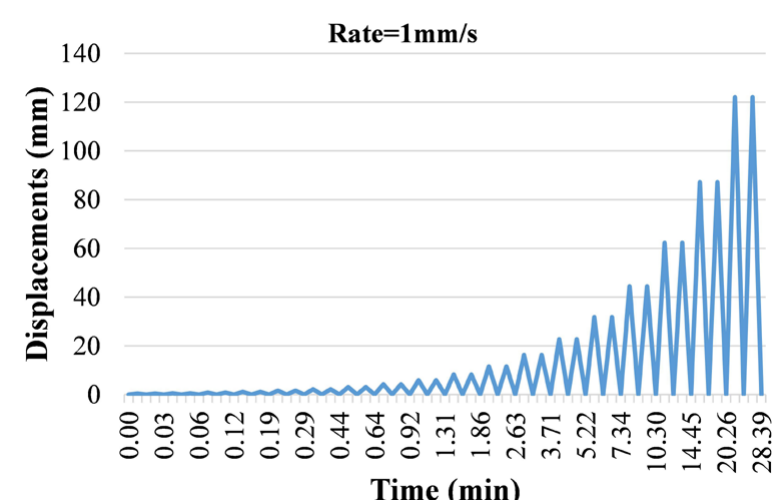

FIGURE 4. Input displacements.

wise increasing deformation amplitudes (Figure 4). Two cycles were completed for each step. The amplitude of each step was 1.4 times the amplitude of the previous step until reaching the target amplitude, which was the deformation level at the peak load of the control beam. The beams were tested until tensile failure of the reinforcement steel.

\subsubsection{Static and cyclic loading tests results}

Figure 5 shows the crack patterns at failure. The specimens (control and strengthened beams) presented a classical flexural failure, developing the same flexural collapse mode with the main crack placed next to the load application point. The observed failure process consisted of (1) the appearance of flexural cracks and their propagation from the tensile side of the specimens to the neutral axis, (2) yielding of the tensile steel reinforcement, (3) stretching of the FRCM grid, and breakage of the FRCM grid; and (4) rupture of the tensile steel and crushing of the concrete in compression.

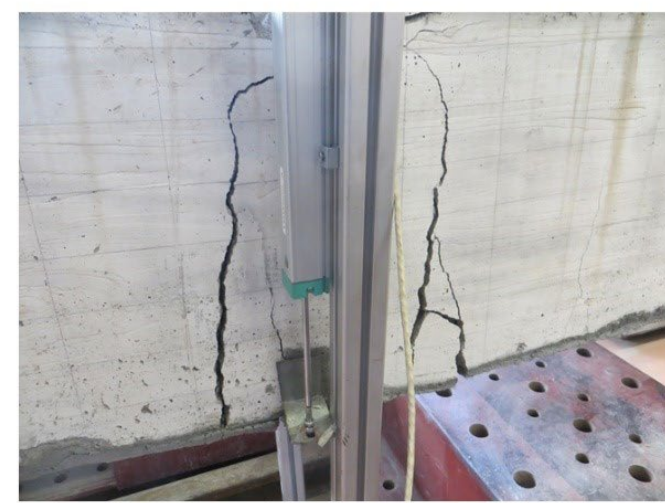

(a)

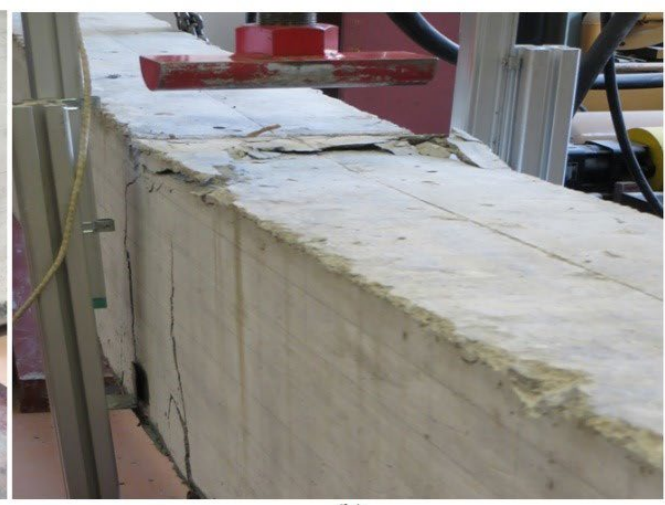

(b)

FiguRE 5. Crack pattern. 


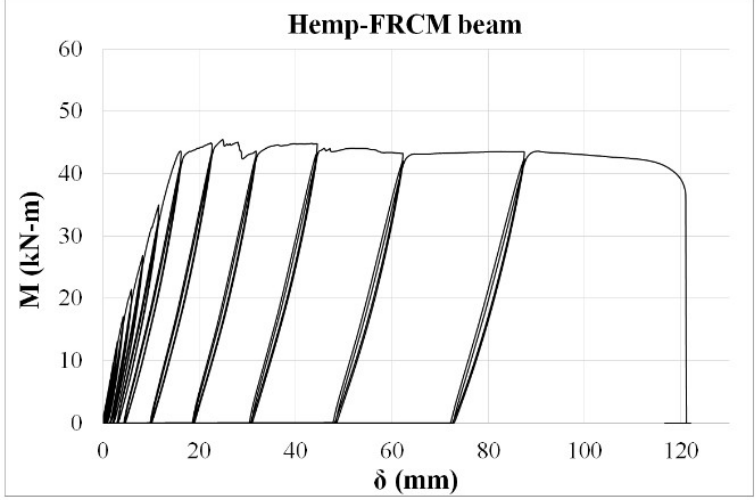

(a)

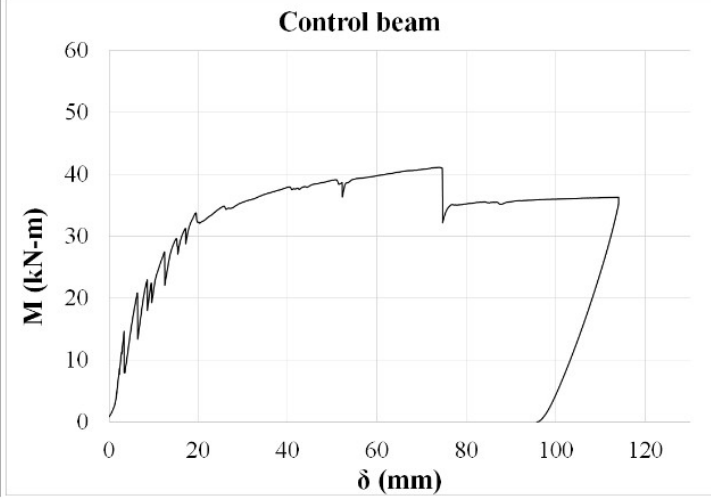

(b)

FigURE 6. Bending moment vs. vertical displacement of: (a) cyclic loading test, (b) static test.

Figure 6 shows the bending moment vs. deflection curves for the cyclic (Figure 6a) and static (Figure $6 \mathrm{~b})$ bending load tests. The former clearly shows the load cycles applied to the strengthened beam, whereas the cracking process of the control beam is observed in the latter plot.

Figure 6 shows that greater bending moment and greater ultimate displacement were achieved by the FRCM-strengthened beam. However, the maximum bending moment occurred for a displacement of approximately $25 \mathrm{~mm}$ in the case of the strengthened beam and about $75 \mathrm{~mm}$ in the case of the unstrengthened beam. This was due to the breakage of the hemp mesh when it reached a displacement of $25 \mathrm{~mm}$. After breaking the mesh, the resisted bending moment began to decrease.

Table 6 lists the results of maximum $\left(\mathrm{M}_{\max }\right)$ and ultimate $\left(\mathrm{M}_{\mathrm{u}}\right)$ bending moments, deflection at the maximum bending moment $\left(\mathrm{y}_{\max }\right)$, and ultimate deflection $\left(\mathrm{y}_{\mathrm{H}}\right)$. Service deflection $\left(\mathrm{y}_{\text {service }}=\mathrm{L} / 300\right)$, which is the least limiting indicated by (29), and the corresponding bending moment $\left(\mathrm{M}_{\text {service }}\right)$ are also included in Table 6.

Table 6 also includes the values of the flexural stiffness (EI). This was analysed at three points of the loading process: in the maximum, ultimate, and service bending moment points. According to the test configuration (Figure 3), the flexural stiffness (EI) developed by the specimens can be expressed as follows [1]:

$$
E I=\frac{F L^{3}}{48 y}
$$

where $\mathrm{F}$ is the total applied load, " $y$ " is the vertical displacement at the mid-span section, and $\mathrm{L}$ is the free span between the supports $(4200 \mathrm{~mm})$.

The values obtained for the flexural stiffness are useful for examining the general behaviour trends of the applied composite reinforcements with respect to the flexural stiffness of the entire structure. The changes caused by the FRCM in the flexural stiffness of the RC beams are presented in Figure 7.
TABLE 6. Results of cyclic loading and static test.

\begin{tabular}{lccc}
\hline Beam & Hemp-FRCM & Control & $\Delta(\%)$ \\
\hline $\mathrm{F}_{\text {max }}(\mathrm{kN})$ & 45.51 & 41.16 & 10.56 \\
$\mathrm{M}_{\text {max }}(\mathrm{kNm})$ & 47.79 & 43.22 & 10.56 \\
$\mathrm{y}_{\text {max }}(\mathrm{mm})$ & 24.87 & 73.89 & -66.34 \\
$\mathrm{EI}_{\text {max }}\left(\mathrm{KN}-\mathrm{m}^{2}\right)$ & 2820 & 860 & 227.91 \\
$\mathrm{M}_{\mathrm{u}}(\mathrm{kNm})$ & 44.09 & 38.12 & 15.66 \\
$\mathrm{y}_{\mathrm{u}}(\mathrm{mm})$ & 113.88 & 112.71 & 1.04 \\
$\mathrm{EI}_{\mathrm{u}}\left(\mathrm{KN}-\mathrm{m}^{2}\right)$ & 570 & 500 & 14.00 \\
$\mathrm{y}_{\text {service }}(\mathrm{mm})$ & 14.00 & 14.00 & - \\
$\mathrm{M}_{\text {service }}(\mathrm{kNm})$ & 39.70 & 27.92 & 42.19 \\
$\mathrm{EI}_{\text {max }}\left(\mathrm{KN}-\mathrm{m}^{2}\right)$ & 4170 & 3080 & 35.39 \\
\hline
\end{tabular}

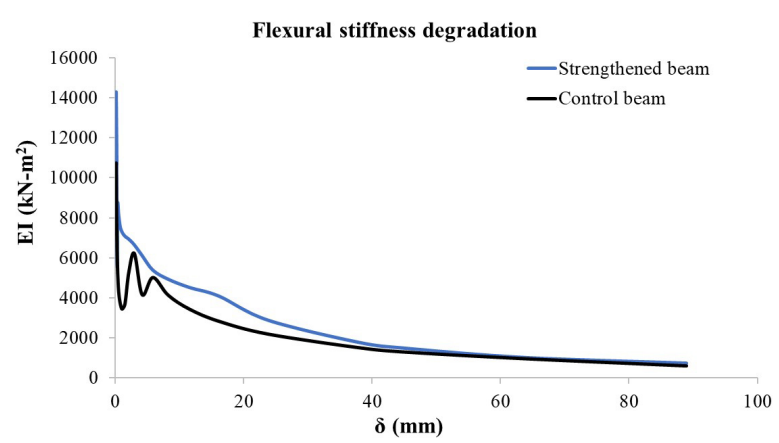

FigURE 7. Flexural stiffness degradation: control beam vs strengthened beam.

According to the results presented in Figure 7 and Table 7, the hemp-FRCM provided an increase in the flexural stiffness. This increase is maximum during the service stage and at the point of maximum bending moment of the strengthened beam. 
The maximum increase in flexural stiffness during the service stage suggests that the FRCM reinforcement is activated at low loading stages. In contrast, the hemp-FRCM did not provide a significant increase in the flexural stiffness with respect to a control beam after reaching the maximum moment. This is in accordance with the evidence found in the flexural capacity analysis, in which FRCM strengthening systems showed less bending improvement capacity as the cracks of the specimens damaged the FRCM.

In addition, comparing the initial flexural stiffness obtained from the experimental bending test with the flexural stiffness obtained from the modal analysis (pre-cracking and strengthened beam), the variation in the initial flexural stiffness was 15\% (10741 kN-m²) for the control beam (pre-cracking value) and $3 \%$ $\left(14279 \mathrm{kN}-\mathrm{m}^{2}\right)$ for the strengthened beam. This highlights the importance of modal analysis results.

According to Table 6, hemp-FRCM strengthening increased all the analysed variables except for the deflection at the maximum moment, which was greater for the control beam. However, for this deflection, the strengthened beam resisted a greater bending moment. The most significant mechanical property enhancement $(42.19 \%)$ corresponded to the bending moment at the service limit state $\left(\mathrm{M}_{\text {service }}\right)$. As long as it was achieved before hemp mesh breaking $(25 \mathrm{~mm})$, it proved the effectiveness of the strengthening system.

Figure 8 shows the M- $\delta$ envelopes for deflection values below those that caused hemp mesh breakage. The contribution of the hemp-FRCM reinforcement to the beam response is clearly observed in this deflection range. In fact, the differences between the control and strengthened beams seem to start at the concrete cracking point, which corresponds to a deflection of approximately $14 \mathrm{~mm}$ when the linear response is completed.

\section{ANALYTICAL MODEL}

The analytical method to determine the ultimate flexural capacity of the strengthened beams is based on the following assumptions: (1) failure of the strengthening composite while the concrete

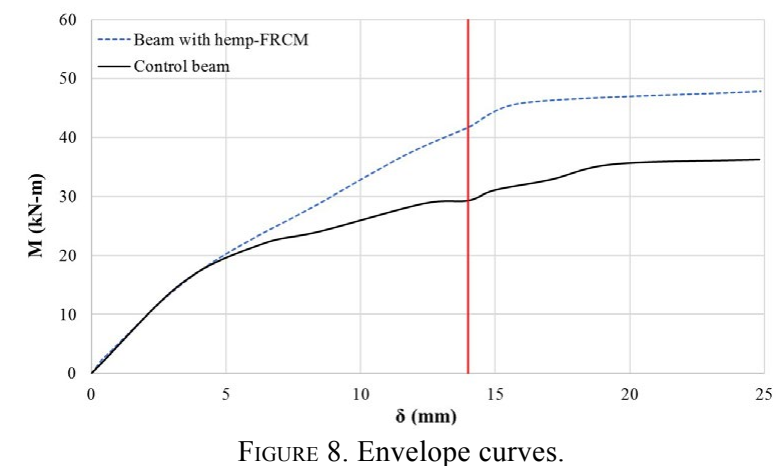

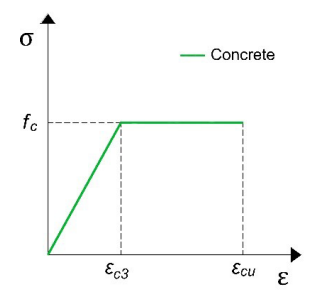

a)

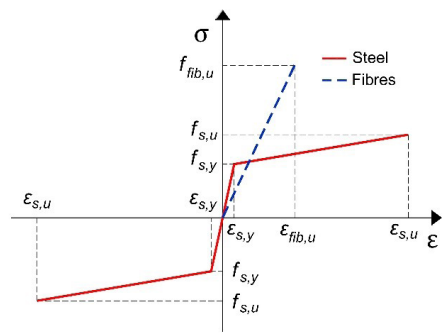

b)
FIGURE 9. Constitutive behaviour of the materials: a) concrete and b) steel and fibres.

substrate and FRCM-concrete bonding maintain their capacities, (2) strain compatibility during the loading process, and (3) equilibrium of forces at the cross-section.

The constitutive behaviour of concrete, steel, and fibres is shown in Figure 9. The first two models were based on Eurocode 2 (30). In the case of concrete in compression, bilinear simplification was considered (Figure 9a). Regarding the steel, an elastic-plastic diagram was used considering the strain hardening phenomenon after yielding (Figure 9b). The fibres are assumed to be linearly elastic until failure (Figure $9 \mathrm{~b}$ ) under tension. The tensile strength of concrete was not considered.

To calculate the maximum bending moment $\left(\mathrm{M}_{\text {max,an }}\right)$, the concrete and tensile steel could reach their ultimate capacities in compression and tension, respectively, according to the considered failure domain. The ultimate strain of the reinforcement steel $\left(\varepsilon_{\mathrm{s}, \mathrm{u}}\right)$ is considered to be $12 \%$, and the ultimate strain of the concrete in compression is considered to be $0.35 \%$, as suggested by EHE (22).

Figure 10 shows the internal force equilibrium and strain distribution of a rectangular $\mathrm{RC}$ beam strengthened with FRCM at the maximum bending moment stage for concrete crushing. In this figure, it can be observed that the model considers different levels of steel reinforcement separately (22). All variables use standard steel-concrete code notations and are depicted in Figure 10.

According to Figure 10, the analytical maximum flexural moment $\left(\mathrm{M}_{\text {max,an }}\right)$ is calculated as follows [Equations 1 and 2]. a)

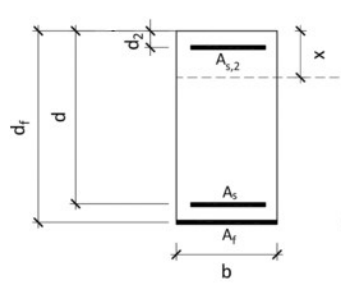

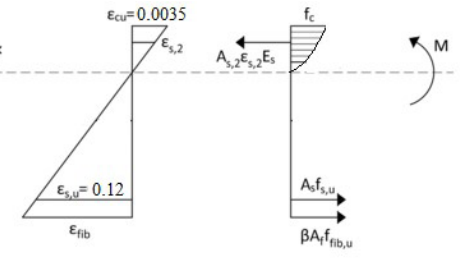

b) c)
FIGURE 10. Analysis of cross-section for the ultimate limit state in bending: a) geometry, b) strain distribution, and c) force equilibrium. 
For beams without FRCM:

$$
M_{\text {max }, \text { an }}=M_{c}+M_{s}+M_{s, 2}
$$

For beams strengthened with FRCM:

$$
M_{\text {max,an }}=M_{c}+M_{s}+M_{s, 2}+M_{f i b}
$$

where $M_{c}, M_{s}, M_{s, 2}$, and $M_{\text {fib }}$ are the ultimate flexural contributions of the concrete, tensile steel reinforcement, compressive steel reinforcement, and fibres of the strengthening system. The contributions of each withstanding material and neutral axis depth (x) can be determined using the following equations [Equations 4-13].

- Ultimate flexural contributions of the concrete

$$
\begin{aligned}
& f_{c}=f_{c d}\left[1-\left(1-\frac{\varepsilon_{c}}{\varepsilon_{c 0}}\right)^{n}\right] \begin{array}{l}
\text { if } 0 \leq \varepsilon_{c} \leq \varepsilon_{c 0} \\
f_{c}=f_{c d}
\end{array} \text { if } \varepsilon_{c 0} \leq \varepsilon_{c} \leq \varepsilon_{c u}
\end{aligned}
$$

The values of the concrete breakage deformation $\left(\varepsilon_{c 0}\right)$ and ultimate deformation $\left(\varepsilon_{c u}\right)$ in compression were set to 0.002 and 0.0035 , respectively. $\mathrm{n}=2$. These values are valid for concrete with a characteristic compressive strength $f_{c k} \leq 50 M P a$.

The moment produced by the compression block will be as follows [6]:

$$
M_{c}=f_{c} A_{c} \bar{x}
$$

where $\left(A_{c}\right)$ is the area of the compression block and $\bar{x}$ is the distance from its centre of gravity to the neutral fibre.

- Tensile steel reinforcement

$$
\begin{array}{cc}
f_{s, u}=\varepsilon_{s} E_{s} & \text { if } \varepsilon_{s}<\varepsilon_{s, y} \\
f_{s, u}=\varepsilon_{s, y} E_{s} & \text { if } \varepsilon_{s} \geq \varepsilon_{s, y} \\
M_{s}=A_{s} f_{s, u}(d-x)
\end{array}
$$

where $\varepsilon_{s, y}$ is the elastic limit deformation, and $\varepsilon_{s, y}=\frac{f_{s, y}}{E_{s}}$.

- Compressive steel reinforcement

In this case, the same criteria as in Equation 6 are fulfilled. The bending moment is calculated using the following equation:

$$
M_{s, 2}=f_{s, u} A_{s, 2}\left(x-d_{2}\right)
$$

- $\quad$ Fibres of the strengthening system

$$
M_{f i b}=f_{f i b, u} A_{f}\left(d_{f}-x\right)
$$

where $A_{f}$ is the area of fibres, $f_{\text {fib, }}$ is the tensile strength of the fibre, and $d_{f}$ is the distance from the FRCM reinforcement fibres to the most compressed fibre of the concrete.

In addition, this study also raises the possibility of using a formulation to introduce the contribution of the tensile strength of the cementitious matrix. This approach is based on the law of mixtures, where

$$
\begin{gathered}
M_{F R C M}=f_{F R C M} A_{\text {hom }}\left(d_{f}-x\right) \\
A_{\text {hom }}=\mathrm{A}_{f} v_{f}+A_{m} v_{m} \\
f_{F R C M}=f_{f} v_{f}+f_{t, m} v_{m}
\end{gathered}
$$

In the case of the FRCM-reinforced beam, it is known that the hemp mesh breaks before other materials. In this case, the mesh ultimate deformation $\left(\varepsilon_{f, u}\right)$ is used to determine the point where the maximum load is reached.

For the control beam, it is considered that the crushing failure of concrete occurs before the breakage of steel. The compressive ultimate deformation of concrete is taken $\left(\varepsilon_{c, u}=0.0035\right)$ to set the point at which the maximum tension is reached in this case. Once the ultimate deformations of the materials are known, the following conditions must be satisfied:

$$
\begin{array}{ll}
\checkmark & \varepsilon_{c} \leq 0.0035(\text { Code }(22)) \\
\checkmark & \varepsilon_{s} \leq 0.12(\text { Code }(22)) \\
\checkmark & \varepsilon_{f} \leq 0.013(\text { Experimental }(14))
\end{array}
$$

Hence, this analytical model considers material failure but does not consider other failures, such as debonding of the FRCM strengthening system. Note that this case represents a desirable situation for practitioners, in which the FRCM may develop its maximum tensile capacity as a flexural strengthening material.

\subsection{Analytical model results}

The results obtained from the analytical model are presented in Table 7. This shows the results of force (F) and maximum bending moment $\left(\mathrm{M}_{\max }\right)$ supported by the hemp-FRCM-strengthened beam and the control beam. Two models are presented for the strengthened beam: model 1 (M1), which assumes that the FRCM properties are directly those of the hemp mesh, and model 2 (M2), which assumes a homogenised area $\left(\mathrm{A}_{\text {hom }}\right)$ and a homogenised tensile stress $\left(f_{F R C M}\right)$, taking into account the contribution of the cement matrix. Both models showed that section failure occurred when the maximum tensile strain of the FRCM was reached. In the case of the control beam, only one model was used, which was associated with the concrete crushing failure $\left(\varepsilon_{C}=0.0035\right)$. 
TABLE 7. Analytical model results.

\begin{tabular}{|c|c|c|c|c|c|c|c|c|c|c|c|}
\hline $\begin{array}{l}\text { Beam } \\
\text { state }\end{array}$ & Model & $F(k N)$ & $M_{\max }(k N-m)$ & $\varepsilon_{\mathrm{c}}(/)$ & $\varepsilon_{\mathrm{s}}(/)$ & $\varepsilon_{\mathrm{s} 2}(/)$ & $\varepsilon_{\mathrm{f}, \mathrm{u}}(/)$ & $\begin{array}{c}\mathbf{f}_{\mathrm{ck}} \\
\text { (MPa) }\end{array}$ & $\begin{array}{c}\mathbf{f}_{\mathrm{ys}} \\
(\mathrm{MPa})\end{array}$ & $\begin{array}{l}\mathbf{A}_{\mathrm{FRCM}} \\
\left(\mathbf{m m}^{2}\right)\end{array}$ & $\begin{array}{c}\mathbf{f}_{\mathrm{FRCM}} \\
(\mathrm{MPa})\end{array}$ \\
\hline \multirow{5}{*}{$\begin{array}{c}\text { Beam } \\
\text { with } \\
\text { hemp- } \\
\text { FRCM }\end{array}$} & $\mathbf{M}_{1}$ & 42.40 & 44.52 & 0.00110 & 0.01074 & 0.00031 & 0.013 & 30 & 500 & 23.55 & 520.00 \\
\hline & $\mathbf{M}_{2}$ & 45.80 & 48.09 & 0.00123 & 0.01211 & 0.00034 & 0.013 & 30 & 500 & 1953.45 & 11.08 \\
\hline & Exp. & 45.51 & 47.79 & - & - & - & 0.013 & 30 & 500 & - & - \\
\hline & $\Delta_{1}(\%)$ & \multicolumn{2}{|c|}{-6.84} & & & & & & & & \\
\hline & $\Delta_{2}(\%)$ & & 64 & & & & & & & & \\
\hline \multirow{3}{*}{$\begin{array}{c}\text { Control } \\
\text { beam }\end{array}$} & $\mathbf{M}_{1}$ & 38.78 & 40.72 & 0.00350 & 0.05055 & -0.0001 & - & 30 & 500 & - & - \\
\hline & Exp. & 41.16 & 43.22 & - & - & - & - & 30 & 500 & - & - \\
\hline & $\Delta_{1}(\%)$ & \multicolumn{2}{|c|}{-5.78} & & & & & & & & \\
\hline
\end{tabular}

$\mathrm{M}_{1}=$ Analytical model 1, $\mathrm{M}_{2}$ : Analytical model 2, Exp: Experimental results, $\Delta_{1}$ : Variation of model 1 with experimental results, $\Delta_{2}$ : Variation of model 2 with experimental results

The first aspect to highlight in the data of Table 7 is that the hemp fabric broke before the concrete crushing failure or steel tensile failure was reached for the strengthened beam. This agrees with the experimental observations. In the case of the control beam, failure by crushing of concrete occurred before breakage of steel.

In the case of the beam with FRCM, both models 1 and 2 properly approximated the experimental results. The best fit was for model 2 (0.64\% variation). This demonstrates that considering the matrix contribution yields more accurate results for the bending capacity of the strengthened beams.

In general, the results presented in Table 7 demonstrate the accuracy of the presented analytical models for both the strengthened and unstrengthened cases.

\section{NUMERICAL MODELS}

The commercial mechanical simulation software Abaqus $^{\mathrm{TM}}$ 6.14-4 (26) was used to perform the numerical simulations. This choice was based on the aim of using a general purpose and widely available simulation tool capable of representing complex material models. In addition, many previous studies for the analysis of FRCMs and RC have successfully used this software (see, for example, $(31,32)$ ).

\subsection{General constitutive formulations of the materials}

One of the most used approaches for the simulation of FRCMs and RC is based on the assumption of a concrete plastic damage model $(33,34)$. This model is characterised by the definition of two elastic moduli: one corresponding to the elastic zone, and another depending on the damage coefficient, which is a function of the cracking situation or the plasticisation achieved. In this model, it is assumed that the two main failure mechanisms are tensile cracking and compression crushing of concrete. The evolution of the yield surface (or failure) is controlled by two plasticisation variables, $\varepsilon_{t}^{p l}$ and $\varepsilon_{c}^{p l}$, linked to the failure mechanisms under tension and compression, respectively. These are defined as plastic deformations equivalent to tension and compression, respectively.

In addition, this model assumes that the stressstrain response for the uniaxial compression of con-
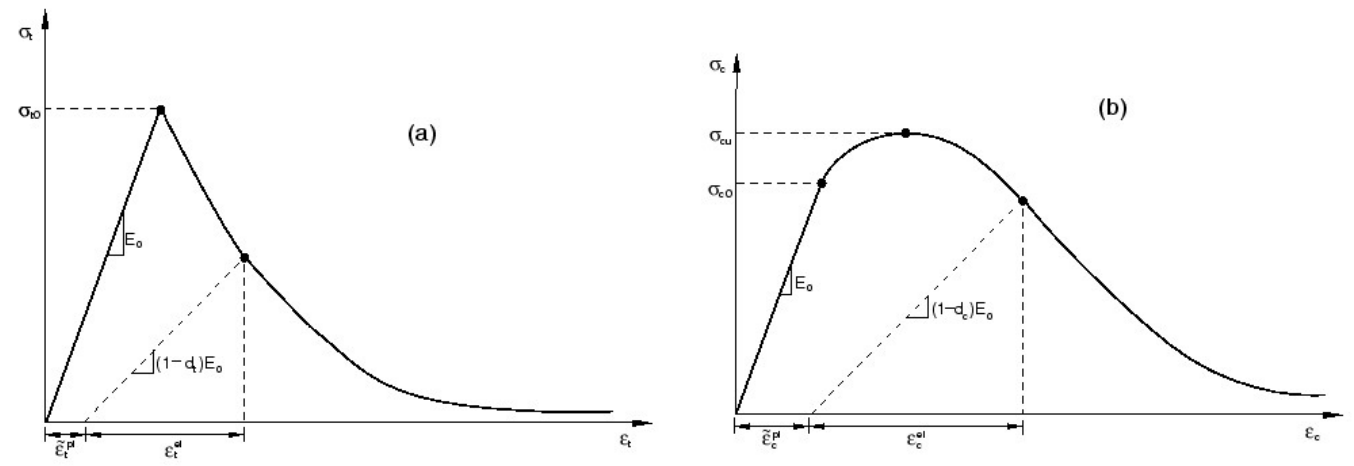

Figure 11. Uniaxial model (26): (a) tension, (b) compression. 
crete is characterised by damaged plasticity, as shown in Figure 11. Under uniaxial tension, the stress-strain response follows a linear elastic relationship until the cracking stress value is reached $\left(\sigma_{t 0}\right)$.

The cracking stress corresponds to the appearance of microcracks in the material. From this point, the tensile tension that transmits the material does not disappear, but it gradually decreases as the deformation increases. This behaviour simulates the interaction between reinforcement and concrete or fabric and mortar (FRCM), and provides numerical stability to improve convergence. The damage variable $d_{t}$, whose minimum value is 0 (undamaged material) and maximum value is 1 (totally damaged material), defines the slope of the discharge branch. Therefore, if $\mathrm{E}_{0}$ is the modulus of elasticity of the elastic material, the module of the discharge branch becomes $\left(1-d_{t}\right) E_{0}$.

Under uniaxial compression, the response is linear up to the initial yield $\left(\sigma_{\mathrm{c} 0}\right)$. In the plastic zone, the response is typically characterised by stress hardening, followed by stress weakening beyond the final stress $\left(\sigma_{\mathrm{u}}\right)$. This representation, although somewhat simplified, captures the main characteristics of the concrete response and is also valid for mortar. As in the case of tension, there is a damage parameter $d_{t}$ that varies between 0 and 1 , which reduces the stiffness of the discharge branch.

Regarding the plastic zone of the cementitious matrix under tension, it was necessary to define the following parameters:

a) Dilatation angle: It controls the amount of plastic volumetric deformation developed during the plastic shear and is assumed to be constant during the plastic flexibilisation. The first value used for this parameter was 13. It was chosen on the basis of existing literature (32), but convergence difficulties justified increasing this value up to 30 .

b) Eccentricity: This parameter defines the speed at which the function approaches the maximum stress asymptote. The predetermined eccentricity suggested by Abaqus is 0.1 , which implies that the material has almost the same angle of expansion in a significant range of confining pressure values.

c) Form parameter of the plasticising surface K: This is the ratio of the second invariant tension in the meridian to that of the compression meridian in the initial yield for any given value of the invariant pressure. The default value was $2 / 3$.

d) Relationship between maximum uniaxial and biaxial compression stresses at the beginning of the loading process. The default value was 1.16.

e) Viscoplastic regularisation: models of materials that exhibit a smoothing behaviour and degradation of rigidity often lead to serious convergence difficulties in implicit analysis programs.
A common technique for overcoming some of these convergence difficulties is the use of a viscoplastic regularisation of the constitutive equations, which causes the constant tangent stiffness of the softening material to become positive during sufficiently small increments of time. Values of $0.00001,0.0001,0.001,0.002$, and 0.003 were tested for an objective choice, proving that 0.00001 (for the beam) and 0.003 (for the FRCM) were the only values that allowed model convergence.

Once these material properties were defined, the matrix stress-strain curves and the corresponding damage variables were calculated. To calculate these damage variables, the procedure indicated by (32) was followed.

\subsection{FRCM modelling}

To define the mechanical properties of the FRCM to be used to model the strengthening of the concrete beam, it was necessary to first implement and validate a numerical model of previous FRCM experimental tensile tests (35). This model assumed the following geometric definition of the tensile FRCM specimens: length of $200 \mathrm{~mm}$ (free length of FRCM tensile specimen), width of $50 \mathrm{~mm}$, and thickness of $10 \mathrm{~mm}$. This geometry, corresponding to the matrix, is defined as a deformable solid part.

To simulate the hemp fabric, truss elements were chosen, as in other studies (35). These long and thin structural members can transmit axial force only, and they are typically used to model thin, line-like structures that support loading only along the axis of the element. No moments or forces perpendicular to the centre line were considered with this element. Truss elements were used in this case to reduce the high computational costs caused by the use of three-dimensional elements, as well as to avoid convergence problems. In addition, the good adherence shown by the vegetal fabrics covered with epoxy and embedded into a cement matrix in (35) justified considering the fabric to be completely bonded to the matrix without allowing slipping in the fabricmatrix interface.

In the FRCM model, four "truss" elements were used. These simulated four longitudinal hemp fabric tows were embedded in the FRCM specimens. The tows in the weft direction were not simulated because the adhesion contribution of the tows placed in the weft direction was neglected when only tensile axial loads were applied.

Two types of materials were defined: one corresponding to the deformable solid that represented the cementitious matrix, and the other corresponding to the truss element that represented the tufts in the warp direction of the vegetal fabric. 
The aforementioned plastic damage model was chosen to define the material of the cementitious matrix. The tensile elastic behaviour of the cementitious matrix was experimentally determined by compression and tensile tests of mortar specimens (see Table 1 in (14)), and the Poisson coefficient, which was set to 0.2 , as suggested by EHE (22).

Regarding the boundary conditions, one of the transverse faces of the mortar model (deformable solid) was fixed (restriction of displacement in all directions), and a displacement equivalent to the integration of a constant strain equal to the ultimate fabric strain was imposed on the opposite face.

Two meshes with characteristic size of 2 and 5 $\mathrm{mm}$ were tested for the convergence analysis, and no significant difference was observed in the results ( $3 \%$ variation in the failure strain). Hence, the size of the elements used was set to $5 \mathrm{~mm}$ for all the parts to reduce the calculation cost. The resulting mesh had 800 solid elements and 160 truss elements (Figure 12). An implicit structural analysis was performed.

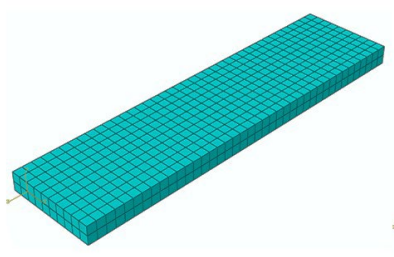

(a)

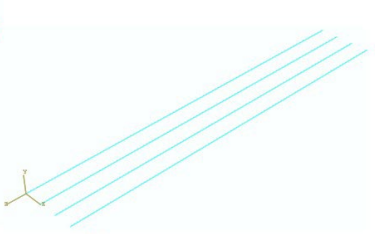

(b)
FIGURE 12. FRCM mesh: (a) deformable solid, (b) truss type element.

\subsubsection{Results of the numerical model of FRCM}

The results of the numerical simulation of the tensile specimens of hemp-FRCMs are presented in Table 8 . The table lists the results of the cracking stress $\left(\sigma_{\mathrm{mc}}\right)$ and ultimate stress $\left(\sigma_{\mathrm{cu}}\right)$ obtained for each model based on the relationship between the reaction force (obtained by Abaqus) and the cross-sectional area of the FRCM $\left(500 \mathrm{~mm}^{2}\right)$. Table 8 also presents the percentage of variation with respect to the experimental $\left(\Delta_{\text {exp }}\right)$ and analytical $\left(\Delta_{\mathrm{a}}\right)$ results obtained in (14).

The elastic moduli of zones $1\left(\mathrm{E}_{\mathrm{I}}\right)$ and $3\left(\mathrm{E}_{\mathrm{III}}\right)$ obtained from the first slope (before the tensile cracking stress) and the second ascending slope (linear part in the slope after tensile cracking) in the stressstrain diagrams (see Figure 13) are also summarised in Table 8.

Figure 13 shows a better fitting between the analytic and numerical results than with the experimental ones. The proposed numerical model was unable to reproduce the increase in unstable tensions due to the fabric-matrix interaction.
TABLE 8. Results of the numerical model of FRCM subjected to tensile load.

\begin{tabular}{lcccc}
\hline Fibres & $\boldsymbol{\sigma}_{\mathrm{mc}}(\mathbf{M P a})$ & $\boldsymbol{\sigma}_{\mathrm{cu}}(\mathbf{M P a})$ & $\mathbf{E}_{\mathbf{I}}(\mathbf{G P a})$ & $\mathbf{E}_{\mathrm{III}}(\mathbf{G P a})$ \\
\hline Hemp & 4.97 & 7.36 & 9.25 & 0.45 \\
$\Delta_{\text {exp }}(\%)$ & -9.71 & 3.81 & -56.99 & -23.14 \\
$\Delta_{\mathbf{a}}(\%)$ & 3.03 & 10.50 & -0.77 & 14.31 \\
\hline
\end{tabular}

The difference between the cracking and ultimate tension calculated by the numerical model to the experimental results ranges from $3 \%$ to $10 \%$; therefore, this model is an effective calculation tool for the analysis of FRCMs with hemp fibres if there is sufficient interaction between the mesh and matrix. This allowed us to define the mechanical properties of the hemp-FRCM used to simulate the strengthened concrete beam in Section 4.3.2.

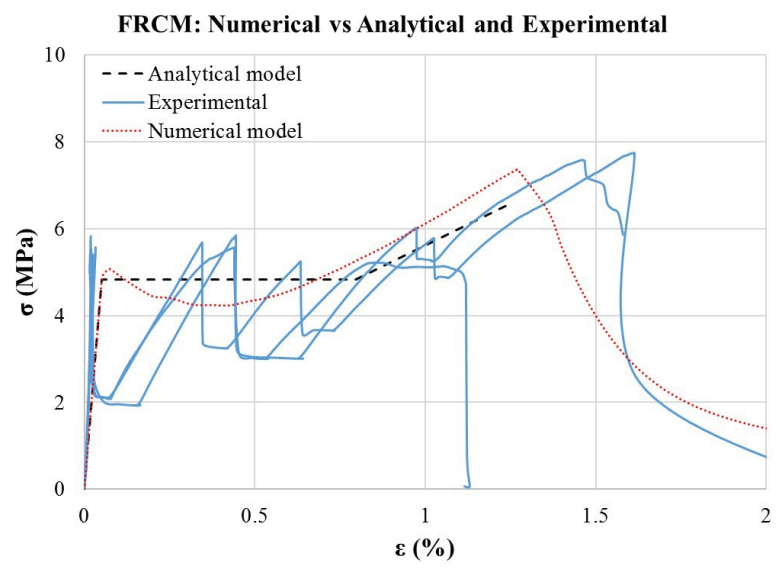

FIgURE 13. Stress-strain diagrams: numerical vs analytical vs experimental results.

\subsection{Numerical model of beams}

For simulation of the FRCM, Abaqus ${ }^{\mathrm{TM}}$ 6.14-4 (26) was also used. Two types of beams were analysed: unstrengthened (control beam) and hempFRCM-strengthened beams.

\subsubsection{Unstrengthened beam model}

For this analysis, a deformable solid was used to simulate the concrete part defined by a length of 4.5 $\mathrm{m}$, width of $200 \mathrm{~mm}$, and height of $400 \mathrm{~mm}$ (Figure $14 a)$.

Truss elements were used to simulate the steel reinforcement (longitudinal steel bars and stirrups). The steel elastic-plastic model suggested by the code (22) was assigned to these reinforcement elements. 
A concrete damage plastic model (previously used for mortar in the FRCM simulation) was used to define the concrete response. The corresponding material properties were obtained as follows. The concrete tensile strength (corresponding to the cracking state) was calculated using Equation 14 and 15 (23), resulting in a value of $f_{m t}=0.23 \mathrm{MPa}$.

$$
\begin{gathered}
f_{m x}=1.5 \frac{F_{\max } L}{b h^{2}} \\
f_{m t}=f_{m x} \frac{1.5\left(\frac{h}{100}\right)^{0.7}}{1+1.5\left(\frac{h}{100}\right)^{0.7}}
\end{gathered}
$$

where $f_{m x}$ is the experimentally obtained flexural cracking strength of the RC beam. $F_{\text {max }}$ is the maximum force applied in the three-point test, and L is the distance between the beam supports. $b$ and $h$ are cross-sectional dimensions of the beam.

The static elastic modulus of concrete determined in the modal analysis (Section 2.2.1) was used to define its elastic properties.

Two mesh sizes for concrete discretisation were tested for the convergence analysis: 0.05 and 0.025 $\mathrm{m}$. The $0.05 \mathrm{~m}$ sized mesh was chosen because no significant difference between the 0.05 and $0.025 \mathrm{~m}$ meshes was observed $(4.7 \%$ variation of the maximum reaction force), and the calculation time was 30 times less using the $0.05 \mathrm{~m}$ mesh.

The boundary conditions were set according to the static loading setup adopted in Section 2.4 (Figure 3). The displacements in the " $y$ " and " $x$ " directions in one support and the displacements in the " $y$ " and " $z$ " directions in the other one were restrained (see Figure 14).

A steel solid (length of $0.2 \mathrm{~m}$, wide of $0.1 \mathrm{~mm}$ and height of $0.1 \mathrm{~mm}$ ) was modelled to simulate the loading tool. The load was indirectly applied by imposing a vertical displacement that caused the failure of the experimental specimen (Section 2.5).

Finally, to identify and verify the breaking condition, the concrete compressive ultimate strain $(0.0035)$ was considered as the governing criterion.

\subsubsection{FRCM-strengthened beam model}

In the case of the beam strengthened with hempFRCM, the same unstrengthened beam model was used, with the difference that shell elements were added to simulate the FRCM (see Figure 14c). This type of element was previously used by Zhang et al. (36) to simulate masonry walls strengthened with FRP.

Shell elements are intended to model structures with one dimension significantly smaller than the other two dimensions. The stresses in the thickness direction must be negligible to properly use the shells. An elastic-plastic model was used on the shell elements to represent the FRCM. The numerical stress-strain diagram presented in Figure 13 was used, and thus a discharge slope had to be defined to facilitate convergence. This was calculated using the same procedure used to calculate the discharge slope in the tensile concrete damage model used for the FRCM, as described in Section 4.1.

For the interaction between shell elements (FRCMs) and deformable solids (concrete beams), tie connections were used. This approach has been considered in other studies $(36,37)$. Tie contact is a link restriction that allows merging two regions even though the meshes created on the surfaces of the regions may be different, and therefore complete beam-FRCM bonding was assumed.

The same boundary condition as that for the unreinforced beam was imposed. The input displacements were set according to the adopted cyclic loading setup (Figure 4).

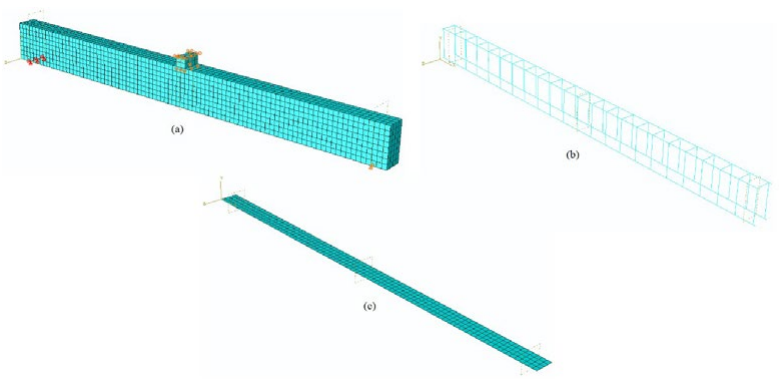

Figure 14. Numerical model of beam: (a) deformable solid-beam, (b) truss elements-reinforcement steel, (c) Shell element-FRCM.

\subsubsection{Results of the beams' numerical models}

Figure 15 shows the strain contour plots of the concrete beam, FRCM, and reinforcement steel at the state when the entire structural element reached the maximum reaction force. This occurred when the ultimate strain of the hemp fabric was reached. It can also be observed that the strain in the reinforcement steel did not reach its ultimate value $(0.12)$, and no concrete crushing strain $(0.0035)$ was reached. These results confirm that the FRCMs broke before the other materials.

The results obtained from the numerical model are presented in Table 9. The table lists the maximum bending moment $\left(\mathrm{M}_{\text {max }}\right)$, deflection at the maximum moment $\left(\mathrm{y}_{\max }\right)$, service bending moment $\left(\mathrm{M}_{\text {service }}\right)$, and maximum strain in the reinforcement steel $\left(\boldsymbol{\varepsilon}_{\mathrm{s}}\right)$ and FRCM $\left(\boldsymbol{\varepsilon}_{\mathrm{f}, \mathrm{u}}\right)$.

The fitting capabilities of the numerical model are analysed for both beams as follows:

a) Control beam: the maximum and service moment and the deflection at maximum moment 


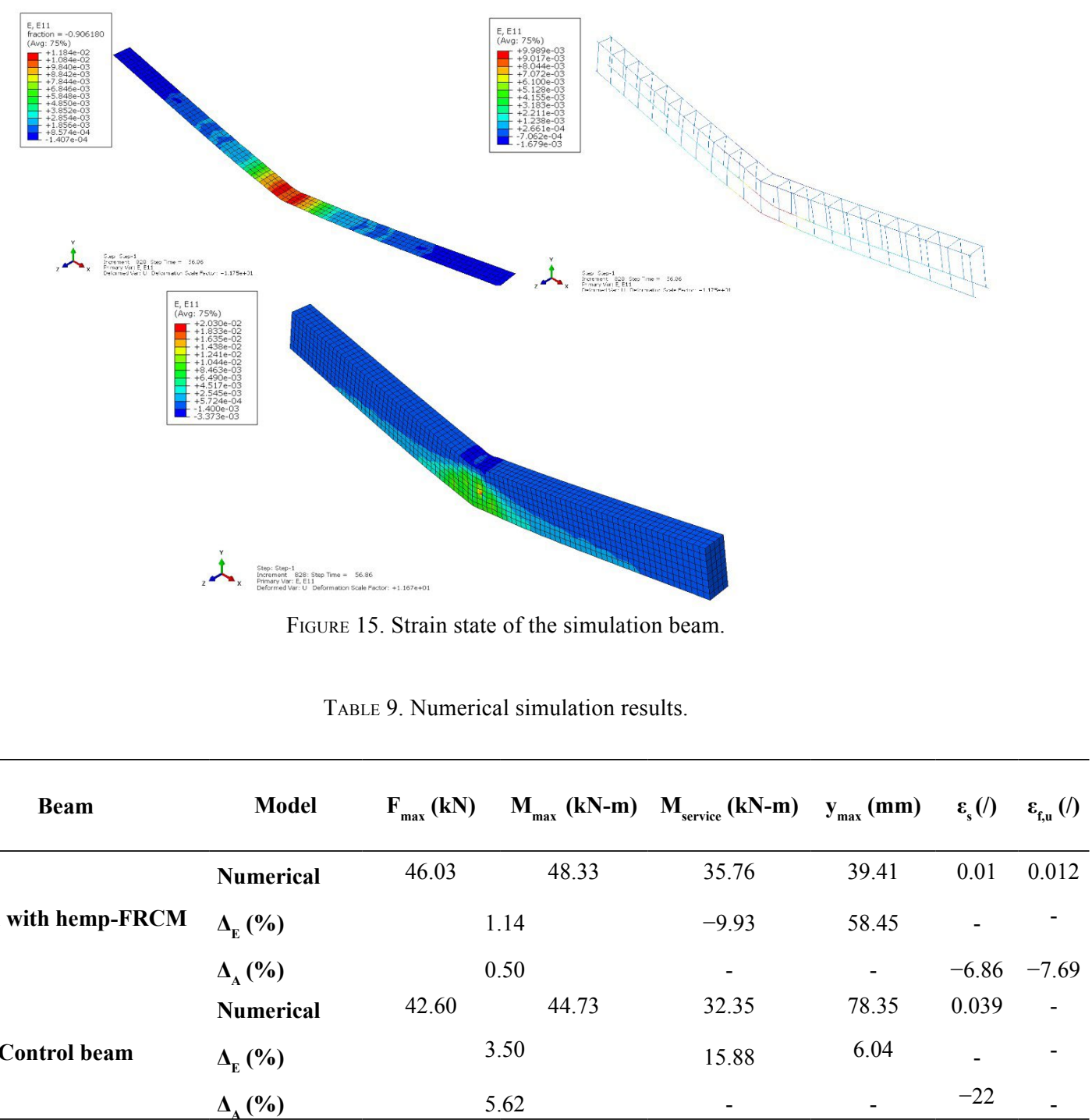

$\Delta_{\mathrm{E}}$ : variation with respect to experimental test, $\Delta_{\mathrm{A}}$ : variation with respect to the analytical results

properly fit the experimental and analytical results, with differences ranging between $3.5 \%$ and $16 \%$. However, the numerically predicted maximum strain of the steel was much lower than that of the analytical model $(22 \%)$.

b) Beam strengthened with hemp-FRCM: the model for the strengthened beam was able to obtain values of maximum moment, service moment, and strain in the reinforcement steel $\left(\varepsilon_{\mathrm{s}}\right)$ and FRCM $\left(\varepsilon_{\mathrm{fu}}\right)$ close to the experimental and analytical results, with differences ranging from $0.5 \%$ to $10 \%$. However, in the case of the deflection at the maximum moment, the numerical model yielded a far lower value than the experimental tests $(58 \%)$.

Figure 16 shows the complete moment-deflection curves for both beams, including the experimental and numerical results.
Figure 16b shows an accurate fitting between the experimental and numerical hysteretic responses of the cyclic test on the strengthened beam. However, it is appreciated that the permanent strains predicted by the numerical model are greater than the experimental ones. This indicates the inability of the model to reproduce the reversible crack opening-closing observed in the experimental tests.

Figure 17a presents the stiffness degradation of the strengthened beam with an increase in the displacement cycles. The stiffness degradation $\left(\mathrm{K}_{\mathrm{i}}\right)$ was determined from the relationship between the average of the sums of absolute values of maximum load per cycle and the average of the sums of absolute values of maximum displacement per cycle (see Equation 16).

$$
K_{i}=\frac{\left|F_{i}^{-}+F_{i}^{+}\right|}{\left|\delta_{i}^{-}+\delta_{i}^{+}\right|}
$$




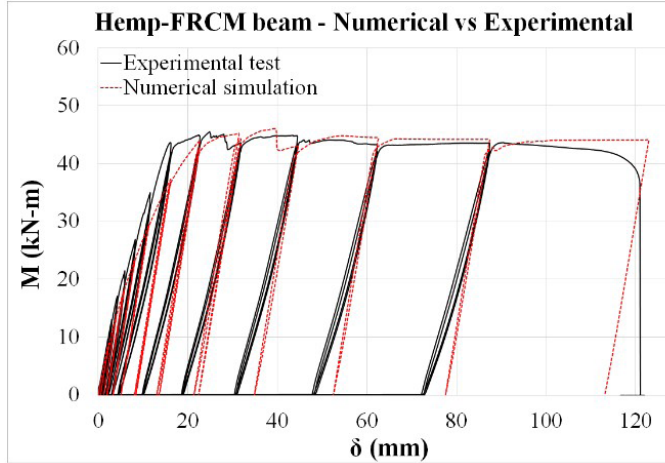

(a)

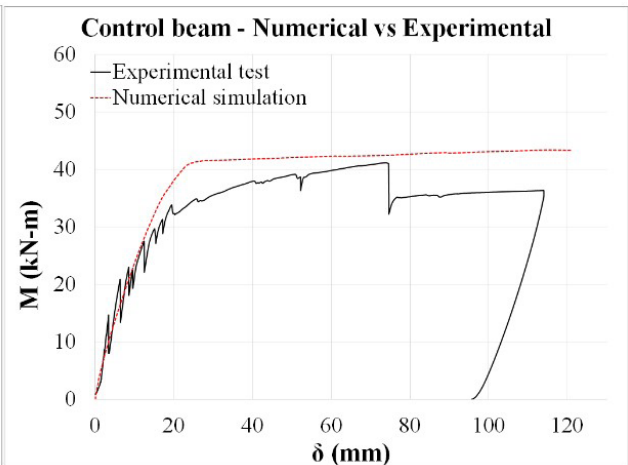

(b)

FIGURE 16. Moment-deflection diagram: (a) static load (control beam), (b) cyclic load (strengthened beam).

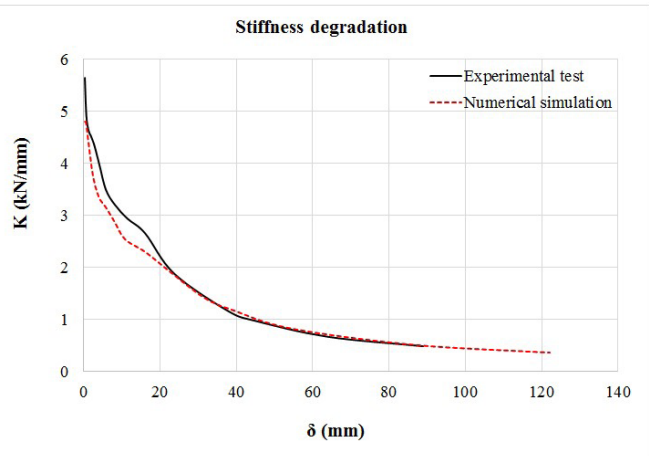

(a)

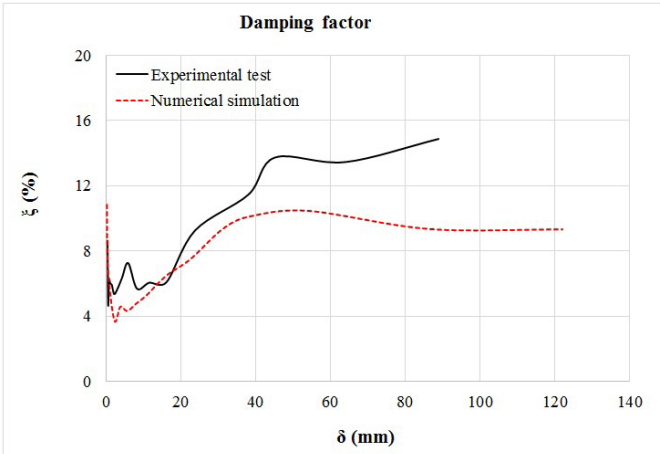

(b)

FIGURE 17. Strengthened beam: (a) stiffness degradation and (b) damping factor.

Figure 17a. shows that the stiffness degradation coefficient from the numerical model approaches the stiffness coefficients of the experimental results. This fact proves the effectivity of the model for representing significant damage processes.

To evaluate the energy dissipation capacity of the strengthened beam, the viscous damping factor was determined for each loading cycle ( $\xi \mathrm{i})$. This parameter is defined as the capacity of a structure to dissipate the input energy (Epi). The damping factor for each cycle can be determined using the following equation:

$$
\xi_{i}=\frac{1}{2 \pi} \frac{E_{d i}}{E_{p i}}
$$

where $E_{d i}$ is the dissipated energy (envelope area in the hysteresis curves).

Figure $17 \mathrm{~b}$ shows the evolution of the damping factor during the loading process. This figure shows more variation between the numerical and experimental results than the stiffness degradation plot, although the general tendency shows agreement. This may be due to the difficulty in reproducing the reversible crack opening-closing (see Figure 16). It should be noted that the numerical model predicts conservative values of the damping factor when compared with the experimental data.

The results presented in this section demonstrate that the proposed numerical models can accurately reproduce the experimental response. These results depend, for the hemp-FRCM strengthened beam, on the fulfilling of the hypothesis that the connections mesh-mortar and mortar-concrete are sufficiently good to avoid sliding and debonding failures.

In general, this study shows how by using a novel vegetable fabric (hemp) it was possible to increase the stiffness of a previously cracked beam by more than $200 \%$ and increase its service load by $42 \%$ (results confirmed by analytical and numerical models). Therefore, this fabric is a competitive reinforcement material to strengthen $\mathrm{RC}$ beams subjected to dynamic loads. In addition to the efficiency demonstrated in this article by the hempFRCM, its use would entail a significant reduction in cost and density as well as a greater environmental sustainability (compared with the synthetic fibre FRCM (37)).

\section{CONCLUSIONS}

An experimental, analytical, and numerical study of a beam strengthened with hemp-FRCM and sub- 
jected to cyclic loading was conducted. It was complemented with a control case. The following conclusions were drawn from this research:

- The modal analysis of the beam strengthened with hemp-FRCM showed an increase of $270 \%$ in the flexural stiffness of the beam after cracking, demonstrating the effective contribution of the hemp-FRCM to the stiffness of the beam. These results were corroborated by experimental bending tests.

- The experimental results showed that the greatest contribution of the hemp-FRCM system was the significant increase in the ultimate service limit state of the beam, by over $42 \%$.

- The analytical models confirm that in the case of the beam strengthened with hemp-FRCM, the hemp mesh broke before the crushing failure of concrete or tensile breaking of steel.

- The adjusted analytical model yielded better results (variation of $0.64 \%$ from the experimental results) than the traditional model when calculating the maximum bending moment. This demonstrates the efficiency of introducing the FRCM contribution when calculating the structural response of the hempFRCM-strengthened beam.

- The numerical FRCM model developed in this study was useful for defining the mechanical properties of the FRCM used to simulate the hemp-FRCM-strengthened concrete beam.

- The numerical model for the hemp-FRCMstrengthened beam was effective at predicting the maximum bending moment and displacement. However, it presented an inability to reproduce the reversible crack openings observed in the experimental tests.

- The numerical and analytical procedures used to model the FRCM-strengthened beam presented in this study provide a useful calculation tool to reproduce the behaviour of this type of structure when the mechanical bonding in FRCM-concrete and fabric-matrix interfaces is assured.

\section{ACKNOWLEDGMENTS}

The authors gratefully acknowledge partial financial support from the Ministerio de Economía y Competitividad of the Spanish Government through the SEVERUS project (ref. num. RTI2018-099589-B-I00). The authors gratefully acknowledge partial financial support from AZVI, S.A. company through REDUVE contract. Third author is a Serra Húnter fellow.

\section{AUTHOR CONTRIBUTIONS:}

Conceptualization: L. Mercedes. Data curation: L. Mercedes. Formal analysis: L. Mercedes, E. Bernat-Maso, L. Gil. Investiga- tion: L. Mercedes. Methodology: L. Mercedes, E. Bernat-Maso. Project administration: L. Mercedes. Resources: L. Mercedes, V. Mendizával. Software: L. Mercedes. Supervision: L. Mercedes. Validation: L. Mercedes. Visualization: L. Mercedes. Writing, original draft: L. Mercedes, V. Mendizával. Writing, review \& editing: L. Mercedes, E. Bernat-Maso, L. Gil.

\section{REFERENCES}

1. Tahar, H.D.; Abderezak, R.; Rabia, B.; Tounsi, A. (2021) Performance of damaged RC continuous beams strengthened by prestressed laminates plate: Impact of mechanical and thermal properties on interfacial stresses. Coupled Syst. Mech. 10 [2], 161-184. https://doi.org/10.12989/csm.2021.10.2.161.

2. Bisby, L.A.; Roy, E.C.; Ward, M.; Stratford, T.J. (2009) Fibre reinforced cementitious matrix systems for fire-safe flexural strengthening of concrete: Pilot testing at ambient temperature. Adv. Compos. Constr. ACIC 2009 - Proc. 4th Int. Conf. 449-460.

3. Bisby, P.L.; Stratford, T.; Hart, C.; Farren, S. (2013) Fire performance of well-anchored TRM, FRCM and FRP flexural strengthening systems. Adv. Compos. Constr. ACIC 2013 - Conf. Proc. 98-109.

4. Larrinaga, P.; Garmendia, L.; Piñero, I.; San-José, J.T. (2020) Flexural strengthening of low-grade reinforced concrete beams with compatible composite material: Steel Reinforced Grout (SRG). Constr. Build. Mater. 235, 117790. https://doi. org/10.1016/j.conbuildmat.2019.117790.

5. Raoof, S.M.; Bournas, D.A. (2017) TRM versus FRP in flexural strengthening of $\mathrm{RC}$ beams: Behaviour at high temperatures. Constr. Build. Mater. 154, 424-437. https://doi. org/10.1016/j.conbuildmat.2017.07.195.

6. Younis, A.; Ebead, U.; Shrestha, K.C. (2017) Different FRCM systems for shear-strengthening of reinforced concrete beams. Constr. Build. Mater. 153, 514-526. https:// doi.org/10.1016/j.conbuildmat.2017.07.132.

7. Escrig, C.; Gil, L.; Bernat-Maso, E. (2017) Experimental comparison of reinforced concrete beams strengthened against bending with different types of cementitious-matrix composite materials. Constr. Build. Mater. 137, 317-329. https://doi.org/10.1016/j.conbuildmat.2017.01.106.

8. Cevallos, O.A.; Olivito, R.S.; Codispoti, R.; Ombres, L. (2015) Flax and polyparaphenylene benzobisoxazole cementitious composites for the strengthening of masonry elements subjected to eccentric loading. Compos. Part B Eng. 71, 8295 https://doi.org/10.1016/j.compositesb.2014.10.055.

9. Wambua, P.; Ivens, J.; Verpoest, I. (2003) Natural fibres: Can they replace glass in fibre reinforced plastics? Compos. Sci. Technol. 63 [9], 1259-1264. https://doi.org/10.1016/S02663538(03)00096-4.

10. Rosamaria C. (2013) Mechanical performance of natural fiber-reinforced composites for the strengthening of ancient masonry. University of Calabria.

11. Huang, L.; Yan, B.; Yan, L.; Xu, Q.; Tan, H.; Kasal, B. (2016) Reinforced concrete beams strengthened with externally bonded natural flax FRP plates. Compos. Part B Eng. 91, 569578. https://doi.org/10.1016/j.compositesb.2016.02.014.

12. Snoeck, D.; Smetryns, P.A.; De Belie, N. (2015) Improved multiple cracking and autogenous healing in cementitious materials by means of chemically-treated natural fibres. Biosyst. Eng. 139, 87-99. https://doi.org/10.1016/j. biosystemseng.2015.08.007.

13. Cevallos, O.A.; Olivito, R.S. (2015) Effects of fabric parameters on the tensile behaviour of sustainable cementitious composites. Compos. Part B Eng. 69, 256-266. https://doi.org/10.1016/j.compositesb.2014.10.004.

14. Mercedes, L.; Gil, L.; Bernat-Maso, E. (2018) Mechanical performance of vegetal fabric reinforced cementitious matrix ( FRCM ) composites. Constr. Build. Mater. 175, 161-173. https://doi.org/10.1016/j.conbuildmat.2018.04.171.

15. Ardanuy, M.; Claramunt, J.; Toledo-Filho R.D. (2015) Cellulosic fiber reinforced cement-based composites: A review of recent research. Constr. Build. Mater. 79, 115-128. https://doi.org/10.1016/j.conbuildmat.2015.01.035. 
16. Ahmad, H.; Fan, M. (2018) Interfacial properties and structural performance of resin-coated natural fibre rebars within cementitious matrices. Cem. Concr. Compos. 87, 44 52. https://doi.org/10.1016/j.cemconcomp.2017.12.002.

17. Micelli, F.; Aiello, M.A. (2016) Residual tensile strength of dry and impregnated reinforcement fibres after exposure to alkaline environments. Compos. Part B Eng. 159, 490-501. https://doi.org/10.1016/j.compositesb.2017.03.005.

18. Donnini, J.; Corinaldesi, V. (2017) Mechanical characterization of different FRCM systems for structural reinforcement. Constr. Build. Mater. 145, 565-575. https:// doi.org/10.1016/j.conbuildmat.2017.04.051

19. D'Antino, T.; Papanicolaou, C. (2017) Mechanical characterization of textile reinforced inorganic-matrix composites. Compos. Part B Eng. 127, 78-91. https://doi. org/10.1016/j.compositesb.2017.02.034.

20. Shao, Y.; Billington, S.L. (2020) Flexural performance of steel-reinforced engineered cementitious composites with different reinforcing ratios and steel types. Constr. Build. Mater. 231, 117159. https://doi.org/10.1016/j. conbuildmat.2019.117159.

21. EN 12390. Testing hardened concrete. Part 3: compressive strength of test specimens. n.d.

22. Ministerio de Fomento. Comisión Permanente del Hormigón. (2011) EHE-08 Intrucción de hormigon estructural,. 5 Edición

23. EN 1504-3. (2005) EN 1504-3 Products and systems for the protection and repair of concrete structures - Definitions, requirements, quality control and evaluation of conformity Part 3: Structural and non-structural repair.

24. EN 1015-11:2019. (2019) Methods of test for mortar for masonry. Determination of flexural and compressive strength of hardened mortar.

25. Bernat-Maso, E.; Teneva, E.; Escrig, C.; Gil, L. (2017) Ultrasound transmission method to assess raw earthen materials. Constr. Build. Mater. 156, 555-564. https://doi. org/10.1016/j.conbuildmat.2017.09.012.
26. Simulia (2011) Abaqus 6.14. User's Manual.

27. Salman, M.M.; Al-Amawee, A. (2006) The Ratio between static and dynamic modulus of elasticity in normal and high strength concrete. J. Eng. Dev. 10 [2], 163-174.

28. FEMA 461. (2007) Interim Testing protocols for determining the seismic performance characteristics of structural and nonstructural components.

29. Ministerio de Fomento (2019) Documento básico SEseguridad estructural.

30. BS EN 1992-1-1. (2004) Eurocode 2: Design of concrete structures - Part 1-1: General rules and rules for buildings. Br. Stand. Inst. 1, 230 .

31. Bertolesi, E.; Carozzi, F.G.; Milani, G.; Poggi, C. (2014) Numerical modeling of Fabric Reinforce Cementitious Matrix composites (FRCM) in tension. Constr. Build. Mater. 70, 531548. https://doi.org/10.1016/j.conbuildmat.2014.08.006.

32. Alfarah, B.; López-Almansa, F.; Oller, S. (2017) New methodology for calculating damage variables evolution in Plastic Damage Model for RC structures. Eng. Struct. 132 , 70-86. https://doi.org/10.1016/j.engstruct.2016.11.022.

33. Jorge, NL. (2008) Analisis de la aplicacion del metodo de los elementos finitos al modelado de elementos de hormigón armado.

34. Sümer, Y.; Aktas, M. (2015) Defining parameters for concrete damage plasticity model. 1, 149-155.

35. Bertolesi, E.; Milani, G.; Poggi, C. (2016) Simple holonomic homogenization model for the non-linear static analysis of in-plane loaded masonry walls strengthened with FRCM composites. Compos. Struct. 158, 291-307. https://doi. org/10.1016/j.compstruct.2016.09.027.

36. Zhang, S.; Yang, D.; Sheng, Y.; Garrity, S.W.; Xu, L. (2017) Numerical modelling of FRP-reinforced masonry walls under in-plane seismic loading. Constr. Build. Mater. 134, 649-663. https://doi.org/10.1016/j.conbuildmat.2016.12.091.

37. Mercedes, L.; Bernat-Maso, E.; Gil, L. (2020) In-plane cyclic loading of masonry walls strengthened by vegetal-fabricreinforced cementitious matrix (FRCM) composites. Eng. Struct. 221, 111097. https://doi.org/10.1016/j.engstruct.2020.111097. 